\title{
QUANDO ONDE É QUANDO
}

\author{
João Gonçalves Vilela Leandro*
}

Resumo: O presente artigo visa à reflexão acerca da construção do espaço poético como uma estratégia face ao impossível abarcamento do tempo em sua totalidade. Dois espaços específicos da escritura proustiana são observados para orientar essa leitura, Oublis e Combray. Simultaneamente, perquiro como essas categorias de espaço e tempo se relacionam com a noção de inconsciente, conforme o ensino de Jacques Lacan.

Palavras-chave: Espaço; tempo; real; simbólico; imaginário.

Abstract: The present article aims to reflect on the construction of poetic space as a strategy against the impossible embracement of time in its entirety. Two specific spaces from Proust's writing are in focus to guide this reading, Oublis and Combray. Simultaneously, I propose how these categories of space and time are related to the notion of the unconscious, as Lacan's teaching.

Keywords: Space; time; real; symbolic; imaginary.

* Universidade de São Paulo. 
J'ai le temps, que c'est long. ${ }^{1}$ Margarite Duras, Le ravissement de Lol V. Stein

Rua Saint-Hilaire, rua Saint-Jacques, Veneza, Florença, Balbec, Méséglise... tantos lugares... tantos, mas bastaria evocarmos um deles, Combray, para darmo-nos conta da força que a espacialidade assume na obra do romancista francês Marcel Proust, cujo projeto estético parece-nos arquitetado sobre o significante catedral do tempo, o que já nos coloca diante de uma problemática estabelecida pela constante dialética entre o tempo e o espaço na literatura. Tal ideia da catedral como modelo estético para Proust ficaria claramente definida ao longo de seus ensaios, manuscritos, do texto estabelecido de sua obra e em sua correspondência, como se vê na carta de $1^{\circ}$ de agosto de 1919 , enviada ao conde Jean de Gaigneron, em que Proust se comove com a sensibilidade do amigo ao perceber sua obra como uma construção de uma catedral:

et quand vous me parlez de cathédrales, je ne peux pas ne pas être ému d'une intuition qui vous permet de deviner ce que je n'ai jamais dit à personne et que j'écris ici pour la première fois: c'est que j'avais voulu donner à chaque partie de mon livre le titre: Porche I Vitraux de l'abside etc. (PROUST, 1990, p. 359)2

Mas Proust constrói sua obra não apenas em uma espacialidade. Ela é estruturada em uma profusão de detalhes que retarda o tempo da narrativa e do próprio bordejo do espaço. Obra cuja abertura tem como esteio a marca de um significante temporal: "Longtemps, je me suis couché de bonne heure"

\footnotetext{
1 "Tenho tempo, que é longo." (Tradução livre)

2 "E quando você me fala de catedrais, eu não posso não ficar comovido com a intuição com a qual você percebe algo que eu jamais disse a ninguém e que aqui escrevo pela primeira vez: é que eu quis dar a cada parte de meu livro o título: Pórtico I Vitrais da abside etc." (Tradução livre)
} 
(PROUST, 1987, p. 3, grifo meu). ${ }^{3}$ Trata-se, então, de uma catedral, de um espaço, cultivado no tempo. Fita de Möbius em que tempo e espaço literário enleiam-se, fazendo o de dentro e o de fora que constituem uma verdade da obra. No breve tempo de leitura que esse artigo demanda do leitor e no curto espaço pelo qual sua escrita se estende, proponho-me a refletir sobre a filigrana tecida entre as categorias narratológicas de espaço e tempo em alguns momentos da escritura de Marcel Proust, atentando-me sobre como sua escritura tece relações vivas acerca do inconsciente, conforme proposto pelo ensino de Jacques Lacan, questionando, sobretudo, a dureza e a não simbolização do Tempo absoluto, e como o espaço criado pelo narrador é a via para uma tentativa de trazer o tempo perdido, o não sabido, o inconsciente ao seio da linguagem.

Visto que um texto - uma tessitura narrativa - organiza-se na órbita de um significante que gera outros significantes, gostaria de partir de um breve texto presente em Les plaisirs et les jours ("Os prazeres e os dia") intitulado La confession d'une jeune fille ("A confissão de uma jovem moça"). Trata-se de uma narração em primeira pessoa de uma jovem protagonista anônima que, em sua mocidade, havia se entregado aos desejos sexuais de forma inconsequente, o que decepcionaria profundamente sua mãe, caso ela viesse a saber. Passados alguns anos, a heroína tornarase noiva de um jovem cujas qualidades e índole eram notórias. Para ir ao encontro da irmã, o noivo se ausenta por dois dias e, nesse período, a narradora aceita um convite para um jantar no qual se embriaga e se rende às volúpias de um conviva chamado Jacques. Nos aposentos, a heroína, ao se entregar ao conviva, é surpreendida pela sua mãe. Constituída de forma cíclica, essa breve e simplória narrativa termina e se inicia da mesma maneira ou no mesmo ponto: o desejo suicida da narradora por ter traído,

\footnotetext{
3 "Durante muito tempo, costumava deitar-me cedo." (PROUST, 1982, p. 7, tradução de Mário Quintana, grifo meu)
} 
sobretudo, os afetos da mãe. Desde o início, a heroína evoca seu desejo de voltar a Oublis, esse espaço privilegiado de sua infância, marcado fundamentalmente pela presença e ausência da mãe, e ali morrer. Observemos:

Je voudrais aller mourrir aux Oublis, dans le parc où j'ai passé tous mes étés jusqu'à quinze ans. [...] Ma mère m'amenait aux Oublis à la fin d'avril, repartait au bout de deux jours, passait deux jours encore au milieu de mai, puis revenait me chercher dans la dernière semaine de juin. Ses venues si courtes étaient la chose plus douce et la plus cruelle. (PROUST, 1993, p. 139-140, grifos meus) ${ }^{4}$

Essa narrativa, que assume por vezes um tom kitsch e as oscilações de um escritor principiante, seria ora renegada ora admirada, como se vê na carta escrita a Alberto Lumbroso, em 14 de maio de 1920:

Je préfère que vous ne parliez pas de ces pages légères [...]. C'est ne pas que je les renie. Elles pourraient même me faire plaisir si je les relisais, car je me souviens vaguement qu'on y trouva l'embryon des livres d'aujourd'bui, mais elle me feraient seulement de la peine, car j'avais à ce moment là, je crois bien, un certain don de style. (PROUST, 1991, p. 266, grifos meus) ${ }^{5}$

\footnotetext{
4 "Eu gostaria de morrer em Oublis; no parque onde, até quinze anos, passei todos os meus verões. [...] Ao fim de abril, minha mãe me levava a Oublis e partia depois de dois dias. Passava ainda dois dias ao meio de maio e depois voltava para ali ficar na última semana de junho. Suas vindas tão curtas eram a coisa mais doce e mais cruel." (Tradução livre, grifos meus)

5 "Prefiro que você não fale dessas páginas frívolas [...]. Não que eu as renegue. Elas poderiam me dar prazer se eu as relesse, pois me lembro vagamente que nelas encontra-se o embrião dos meus livros de boje, mas elas valeriam à pena, pois eu tinha, no momento em que as escrevi, eu creio, um certo dom do estilo." (Tradução livre, grifos meus)
} 
Outro tom constante em La confession d'une jeune fille é o de pastiche, fazendo explícita referência às Confissões, de Santo Agostinho: "comme l'a dit saint Augustin, il est plus difficile redevenir chaste que de l'avoir été" (PROUST, 1990, p. 148). ${ }^{6}$ Assim, como a heroína da narrativa proustiana em questão, Agostinho teve uma vida de volúpias até o momento de sua conversão: "em minha memória [...] vivem ainda imagens de obscenidades que o hábito inveterado lá fixou" (AGOSTINHO, 2000, p. 245). Ambos os protagonistas têm na figura materna uma chama viva para a boa conduta, embora a heroína falhe diante desse ideal e Agostinho venha aceitar a conversão justamente pelos testemunhos e apelos de sua mãe, Mônica. $O$ pastiche de Marcel Proust estende-se à linguagem marcada por uma culpabilidade e mesmo por notas de uma religiosidade católica, como a epígrafe de L'imitation de Jésus-Christ ("A imitação de Jesus Cristo"), obra atribuída ao místico católico Thomas de Kempis (1379-1471), e ainda a referência às Sagradas Escrituras, quando a heroína, para demarcar temporalmente a consumação de sua traição, evoca o versículo 19 do capítulo 20 do Evangelho de João: "où tout s'est accompli" (PROUST, 1990, p. 149). ${ }^{7}$

Resguardadas as relações que colocam La confession d'une jeune fille no âmbito de um pastiche, gostaria de salientar um aspecto que acredito ser um dos pilares centrais da escritura proustiana e que já encontra suas raízes nessa simples narrativa: a dialética entre o espaço e o tempo. Partamos do nome, pois se sabe que a

onomástica proustiana mostra-se a tal ponto organizada que parece constituir um ponto de partida definitivo de À la recherche du temps perdu: manter um sistema de nomes era, para Proust, e é, para nós, manter as significações essenciais do livro, o arcabouço de seus signos, sua sintaxe profunda. (BARTHES, 2000, p. 165, grifos meus)

\footnotetext{
6 "Como disse Santo Agostinho, é mais difícil voltar a ser casto que ter sido." (Tradução livre)

7 "Onde tudo se consumou." (Tradução livre)
} 
Nota-se, assim, que a onomástica assume um papel de geratriz da significância poética e assim, para além de um pastiche das Confissões de Santo Agostinho, o autor constrói sua escritura em torno de um espaço chamado Oublis, que em francês é a tradução literal de esquecimentos; espaço, portanto, indissociável do tempo que é uma constante abertura e fechamento, uma constante presença e ausência. Oublis faz-se o espaço que traz consigo registros temporais de um passado perdido, distante e tão facilmente chamado de tempo memorialístico - como se de fato ele estivesse apenas ligado à memória e não às tramas imaginárias e simbólicas que se articulam a fim de suplantar o tempo impossível de ser resgatado, em outras palavras, um tempo real. Oublis é um espaço caracterizado pelo lapso, pela gap, pela lacuna tão peculiar ao fluir do tempo:

Nul lieu n'est plus plein de ma mère, tant sa présence, et son absence plus encore, l'imprégnèrent de sa personne. L'absence n'est-elle pas pour qui aime la plus certaine, la plus efficace, la plus vivace, la plus indestructible, la plus fidèle des présences? (PROUST, 1990, p. 139-140, grifos meus) ${ }^{8}$

Pensa-se que a ausência poderia ser aplacada se o tempo perdido reconstituísse o objeto perdido, mas nem tudo de Oublis pode refazer-se, sua plenitude de existência é irrecuperável. Assim, resta à heroína evocar esse espaço-tempo. Todavia, como os espaços parecem ser constituídos no tempo, eles estão fadados à transitoriedade que é a "escassez do tempo e, prossegue Freud, a limitação da possibilidade de uma fruição eleva o valor dessa fruição" (FREUD, 1976, p. 345). Isso faz com que a construção

\footnotetext{
8 "Nenhum lugar é mais repleto das lembranças que tenho de minha mãe, de sua presença e mais ainda de sua ausência, impregnado de sua pessoa. $A$ ausência, não é ela, para aquele que ama, a mais certa, mais eficaz, a mais vívida, a mais indestrutivel, a mais fiel das presenças?" (Tradução livre, grifos meus)
} 
espacial seja uma tentativa de fixar a fruição temporal, fixar o átimo, o instante. Nesse sentido, Oublis, esse significante na gênese da escritura proustiana, demarca o retorno, o valorado retorno ao tempo, à matéria que escoa, e, por um efeito de contiguidade, o retorno e a construção de espaços poéticos.

A fim de dar um tom uníssono aos ecos que o tempo e o espaço produziriam em sua catedral, em sua obra, Marcel Proust valeu-se de um projeto estético que se estenderia por muitos de seus escritos como, por exemplo, em "Swann expliqué par Proust":

Vous savez qu'il y a une géométrie plane et une géométrie dans l'espace. Eh bien, pour moi, le roman ce n'est pas seulement de la psychologie plane, mais de la psychologie dans le temps. Cette substance invisible du temps, j'ai tâché de l'isoler, mais pour cela il fallait que l'expériênce pût durer. (PROUST, 1971, p. 667, grifos meus) ${ }^{9}$

Esse fragmento permite-nos uma análise dos paralelismos nele existentes: géométrie plane estaria para psychologie plane assim como géométrie dans l'espace estaria para la psychologie dans le temps. Dessa forma, a geometria no espaço só se realizaria em uma psicologia no tempo. A preposição em também incita a problemática, pois, mesmo em francês, fala-se de uma psychologie du temps ("psicologia do tempo") e não dans le temps ("no tempo") como usa Marcel Proust, o que sugere uma completa imersão da experiência no tempo e por conseguinte uma construção espacial. Mais ainda: o espaço estrutura-se como um exercício para aprisionar o tempo, uma vez que a experiência tem que durar (fr. durer, durée), ou seja, estender-se. Creio que poderia sistematizar esse fenômeno da seguinte forma:

\footnotetext{
9 "Você sabe que há uma geometria plana e geometria no espaço. Bem, para mim, o romance não é apenas a psicologia plana, mas a psicologia no tempo. Esta substância invisível do tempo, eu tentei isolá-la, mas ao que concerne a essa, seria necessário que a experiência pudesse durar." (Tradução livre, grifos meus)
} 


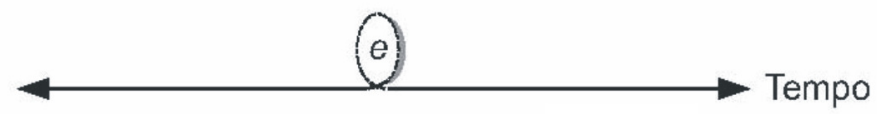

FIGURA 1

O espaço (e) parece-me assumir a forma de projeção do tempo. Averiguemos essa tese, mas agora evocando para além de Oublis, também Combray. Esses dois espaços não seriam o mesmo no processo de criação estética? Não seriam eles o ponto adâmico de uma mitologia da escritura proustiana? Penso que sim, pois ambos se coadunam em uma mesma geratriz de significância poética, em um mesmo significante que é o tempo. O espaço de Oublis não é trabalhado, ele é apenas evocado como um passado gozoso. Há nele poucas descrições, efeitos e construções capazes de projetá-lo aos olhos do leitor, pois "la description modifie surtout, dans le texte, le niveau où l'horizon d'attente du lecteur va se déployer" (HAMON, 1993, p. 41). ${ }^{10} \mathrm{Na}$ figura 1, quis demonstrar que o espaço $(e)$ é justamente essa projeção, essa tentativa de sair da fruição temporal, esse desfiladeiro de conteúdo sem forma, a fim de que o sujeito da narrativa possa se ancorar no seio do simbólico. Fazer a experiência durar só é possível se a enunciação se vale do bic et nunc ("aqui e agora"). Em outras palavras, é na durée ("duração") que o espaço é tecido, é nela que ocorre uma desaceleração temporal, permitindo que haja desdobramentos espaciais.

Ao longo dos estudos críticos sobre Marcel Proust, a durée ocupa um espaço privilegiado, pois, segundo alguns, as influências de Henri Bergson fazem-se evidentes nesse tópico. Em "Swann expliqué par Proust", o romancista viria mesmo rechaçar a presença do bergonismo em sua obra: “je n'aurais aucune honte

\footnotetext{
10 "A descrição modifica, sobretudo, em um texto, o nível no qual o horizonte de expectativa do leitor vai se desdobrar." (Tradução livre)
} 
à dire de 'romans bergsoniens', si je le croyais, car à toute époque il arrive que la littérature a tâché de se rattacher - après coup, naturellement - à la philosophie régnante. Mais ce ne serait pas exact, car mon ouvre est dominée par la distinction entre la mémoire involontaire et la mémoire volontaire, distinction qui non seulement ne figure pas dans la philosophie de M. Bergson, mais est même contradicte par elle" (PROUST, 1971, p. 558) (Tradução livre: "Eu não teria vergonha de dizer 'romances bergsonianos', se eu acreditasse nisso, porque a qualquer momento, acontece da literatura relacionar-se - em retrospecto, é claro - à filosofia reinante. Mas não seria exato, pois minha obra é dominada pela distinção entre memória involuntária e memória voluntária, uma distinção que não só não está na filosofia do senhor Bergson, mas até mesmo contradita por ela."). Mesmo que a problemática da influência de Bergson na obra de Proust não seja resolvida pelas palavras do romancista, creio que a abordagem temporal entre os dois merece ser vista no desenvolvimento que ela gera sobre o narrador. Para o filósofo francês, a durée implica uma velocidade no escoamento do tempo que é na sua essência ontológico e incompreensível. Nesse sentido, a durée é uma experiência ontológica e ponto de partida para outras experiências, sendo que essa fluidez temporal não pode ser apreendida pela inteligência, mas somente pela intuição. A questão do tempo na psicanálise partiria fundamentalmente da ideia freudiana do Nachträglich que seria lida por Jacques Lacan como aprés-coup o que envolve um corte na durée. Esse corte traz à tona a posição do sujeito na tensão entre sua finitude e a infinitude do tempo, restando-lhe, assim, a possibilidade ou não de se posicionar ou ficar à deriva da durée. Parece-me que aqui se estabelece um ponto de crucial diferença entre o tempo e a experiência da durée na filosofia de Bergson e no ensino de Jacques Lacan. Se evocarmos aqui a figura do narrador proustiano para elucidar essa diferença, creio que ele tem uma tomada de posição face ao seu desejo de escrever o tempo em sua obra na medida em que ele consegue simbolizá-lo e não 
ficando mais a sua deriva. Outro ponto de diferenciação seria que Lacan desabona o inconsciente de qualquer ideia memorialística, como algo ôntico no sentido de já estar pronto para vir à luz. Ele, o inconsciente, é, na verdade, algo que se produz em ato, o que lhe confere, assim, o estatuto de lógico e não de cronológico como a durée. Os efeitos do inconsciente podem atuar sobre o ôntico ele, diz-nos Lacan, "c'est que ce n'est ni être, ni non-être, c'est du non-réalisé" (LACAN, 1973, p. 38). ("O inconsciente é que ele não é nem ser nem não-ser, mas é algo de não-realizado." (LACAN, 1998, p. 34, tradução de M. D. Magno)).

Ao contrário de Oublis, o espaço Combray será repleto de descrições: cada conversação, cada rua, os quartos, os jardins, os vitrais de Chartres, tudo toma uma proporção ritualística, seja de um médico cirurgião ou de um pintor cujos pincéis, cores e paleta querem dar contorno ao tempo, detalhá-lo, fixá-lo no espaço:

Combray de loin, à dix lieues à la ronde, vu du chemin de fer quand nous y arrivions la dernière semaine avant Pâques, ce n'était qu'une église résumant la ville, la représentant, parlant d'elle et pour elle aux lointains, et, quand on approchait, tenant serrés autour de sa baute mante sombre, en plein champ, contre le vent, comme une pastoure ses brebis, les dos laineux et gris des maisons rassemblées qu'un reste de remparts du moyen âge cernait çà et là d'un trait aussi parfaitement circulaire qu'une petite ville dans un tableau de primitif. (PROUST, 1987, p. 47, grifos meus) ${ }^{11}$

11 "Combray, de longe, por dez léguas em redor, vista do trem, quando chegávamos na semana anterior à Páscoa, não era mais que uma igreja que resumia a cidade, representava-a, falava dela e por ela às distâncias, e, quando nos aproximávamos, mantinba aconchegados em torno da sua grande capa sombria, em pleno campo, contra o vento, como uma pastora às suas ovelhas, os lombos lanosos e cinzentos das casas reunidas que um resto de muralbas da Idade Média cingia aqui e ali num traço tão perfeitamente circular como uma cidadezinha num quadro de primitivos." (PROUST, 1982, p. 34, tradução de Mário Quintana, grifos meus) 
Notemos que Combray, significante do tempo e do espaço literário, é cercada por muralhas aqui e ali, envolta em uma capa, e minuciosamente suspensa da tensão temporal para ser descrita como uma pastora que guarda suas ovelhas. Posteriormente, o narrador evoca um quadro primitivo, ou seja, esteticamente Proust lança mão da sua intensa admiração pela pintura - sobretudo pelos primitivos flamengos - a fim de capturar cada detalhe do espaço para que a narrativa consiga transpor o tempo para o espaço. Assim,

a psicologia no espaço será aplicada ao nível microscópico [...] para deixar emergir as informações e lembranças acumuladas no decorrer da vida da personagem. Suprimindo o tempo calendário e o espaço, o mineiro cavará, escavará e juntará novas articulações sabendo, tanto quanto Novalis, que "existem dois caminhos para chegar à ciência humana: um penoso $\mathrm{e}$ interminável, com numerosos desvios, o caminho da experiência; outro que é apenas um salto, aquele da contemplação interior". (WILLEMART, 2000, p. 198-9, grifos meus).

A tensão imposta na representação do tempo e do espaço esbarra na problemática de que a espacialidade está para a pintura e a temporalidade para a poesia. G. E. Lessing mostra que a pintura é "a arte que imita corpos em superfície" (LESSING, 2011, p. 91) enquanto "a poesia é uma arte mais ampla” (p. 149). Lê-se nesse jogo de superioridade entre as artes, típico da teoria lessingeana, que a poesia está para o tempo uma vez que é composta pela linguagem que demanda uma sucessão de palavras dispostas em uma cadeia temporal e a pintura está para o espaço, uma vez que lida com a geometria e suas coordenadas. Em seu admirável ensaio "Spatial form in Modern Literature" (1945), Joseph Frank chamanos a atenção para essa dicotomia do tempo e do espaço como proposta por Lessing e critica o que Proust "called 'pure time'. But 'pure time', obviously, is not time at all - it is perception in a moment of time, that is to say, space." (FRANK, 1945, p. 239) 
(Tradução livre: "chamou de 'tempo puro'. Mas o 'tempo puro', obviamente, não é o Tempo - é a percepção em um momento do tempo, isto é, o espaço."). Todavia, creio que a leitura de Frank relaciona a temporalidade na escritura de Proust a partir de uma metalinguagem do narrador, sobretudo no último volume da obra, Le temps retrouvé ("O tempo redescoberto"), não dando ênfase às suas experiências ao longo de toda obra. Um dos únicos momentos evocados por Frank é a epifania na biblioteca da Princesa de Guermantes. Creio que para Proust "o ato criador da recordação, em contraste com o ato mecânico, consiste precisamente em descer como um mergulhador às camadas profundas do eu inconsciente e trazer à luz esses traços, impressões e associações que parecem ter sido perdidos" (MEYERHOFF, 1976, p. 51, grifos meus). Proust solucionaria essa problemática pela projeção do tempo no espaço, como no episódio da lanterna mágica:

On avait bien inventé, pour me distraire les soirs où on me trouvait l'air trop malheureux, de me donner une lanterne magique, dont, en attendant l'heure du dîner, on coiffait ma lampe; et, à l'instar des premiers architectes et maîtres verriers de l'âge gotbique, elle substituait à l'opacité des murs d'impalpables irisations, de surnaturelles apparitions multicolores, où des légendes étaient dépeintes comme dans un vitrail vacillant et momentané. (PROUST, 1987, p. 9, grifos meus) ${ }^{12}$

\footnotetext{
12 "Bem se haviam lembrado, para me distrair nas noites em que me achavam com ar muito melancólico, de presentear-me com uma lanterna mágica, com a qual cobriam minha lâmpada, enquanto não chegava a hora do jantar; $a$ lanterna, à maneira dos primeiros arquitetos e mestres vidraceiros da idade gótica, sobrepunba, à opacidade das paredes, impalpáveis criações, sobrenaturais aparições multicores, onde se pintavam legendas como num vitral vacilante e efêmero." (PROUST, 1982, p. 10-11, tradução de Mário Quintana, grifos meus)
} 
Todo conteúdo de um tempo outro, mítico, como uso feito da lenda de Geneviève de Brabant, ${ }^{13}$ é deslocado para o espaço. $\mathrm{O}$ que era incomunicável, mudo, impossível de vir ao seio do simbólico é agora projetado no espaço em branco da parede. Nesse episódio, o narrador remonta toda lenda - narrativa - merovíngia. Para livrarse da angústia causada pela ausência da mãe, o narrador dá voz à lenda, recria, transforma a fruição brutal do tempo e o vazio que ele causa em um espaço da narrativa, tecendo uma narrativa que lhe fora contada, mas nova na medida em que ele a re-conta fazendo, enfim, suas próprias mil e uma noites. O espaço, como realizado na escritura proustiana, parece-me se dar como uma fenda, uma abertura para a realização simbólica do conteúdo temporal tão próximo da ideia de inconsciente que se produz como o

achoppement, défaillance, fêlure. Dans une phrase prononcée, écrite, quelque chose que vient à trébucher. [...] $L a ̀$, quelque chose d'autre demande à se réaliser - qui apparaît comme intentionnel, certes, mais d'une étrange temporalité. Ce qui se produit dans cette béance, au sens plein du terme "se produire", se présente comme "la trouvaille". C'est ainsi d'abord que l'exploration freudienne rencontre ce qui se passe dans l'inconscient. (LACAN, 1973 , p. 33, grifos meus) ${ }^{14}$

\footnotetext{
${ }^{13}$ As narrativas em torno da personagem Geneviève de Brabant povoam muito mais o universo popular do que propriamente o histórico, possuindo, assim, variações. Filha do Duque de Brabant, Geneviève teria sido desposada pelo palatino Siegfried de Traves que partira em batalha sem saber que sua esposa estava grávida. Ao voltar, Siegfried é influenciado pelo cavaleiro-mor Golo que questionava a fidelidade de Geneviève. Em cólera, o palatino ordena que Golo sacrifique a criança e a mulher. Ele abandonaria os dois em uma floresta. Descoberta a discórdia plantada em seu coração, Siegfried parte à procura da mulher e da criança, encontrando-as em uma gruta e lhes restituindo a vida digna. Essa narrativa foi transformada em ópera por Jacques Offenbach (em 1859) e por Robert Schumann (em 1848).

14 “Tropeço, desfalecimento, rachadura. Numa frase pronunciada, alguma coisa se estatela. [...] $A l i$, alguma coisa quer se realizar - algo que aparece como intencional, certamente, mas de uma estranha temporalidade. O que se produz
} 
Là ("ali"), marcador discursivo de espacialidade, outra forma de dizer: no espaço, o inconsciente pulsa temporalmente e se têm fragmentos de seu conteúdo escritos no simbólico. Não podemos reduzir a escritura proustiana a conceitos clínicos, mas não haveria na literatura um questionamento sobre a subjetividade que nos permite aludir questões do inconsciente? "Se pourrait-il que 'le temps perdu' ne soit que la désignation voilée de la recherche de l'inconscient ou, comme on le nommait à l'époque, de 1'autre moi'?" (BIZUB, 2006, p. 16). ${ }^{15}$ Esse tempo perdido impele a construção de um espaço. A busca desse tempo esteve, como nos adverte o próprio Marcel Proust, entrelaçada à busca de um saber não sabido, de algo inconsciente: "mon livre serait peut-être comme un essai d'une suite de 'Romans de l'Inconscient"' (PROUST, 1971, p. 558) ${ }^{16}$ Pode-se ainda observar que o tempo assume na escritura de Proust um viés de impossível, senão pela via do simbólico e do imaginário. Como elucida Willemart, "o narrador proustiano, situando-se no campo dos três registros lacanianos, tenta remover o Simbólico para penetrar no Real pelo Imaginário inventado" (WILLEMART, 2000, p. 19).

Nesse sentido, a forma que o narrador proustiano encontra é, como já disse, evocando esse tempo perdido e operando seus fragmentos na criação de um espaço poético. Para essa projeção, o narrador se vale não apenas da parede na qual reescreve, reconta, narra a lenda de Geneviève de Brabant. Ele recorre também a pedacinhos pequenos de panos luminosos. Vejamos:

nessa hiância, no sentido pleno do termo 'produzir-se', se apresenta como um 'achado'. É assim, de começo, que a exploração freudiana encontra o que se passa no inconsciente." (LACAN, 1998, p. 137, tradução de M. D. Magno, grifos meus). 15 “Não seria o 'tempo perdido' a designação velada de uma busca do inconsciente ou, como era nomeado na época, de 'outro eu'?” (Tradução livre)

16 "Meu livro pode ser uma tentativa de uma série de 'Romances do Inconsciente."” (Tradução livre) 
C'est ainsi que, pendant longtemps, quand, réveillé la nuit, je me ressouvenais de Combray, je n'en revis jamais que cette sorte de pan lumineux, découpé au milieu d'indistinctes ténèbres, pareil à ceux que l'embrasement d'un feu de bengale ou quelque projection électrique éclairent et sectionnent dans un édifice dont les autres parties restent plongées dans la nuit. (PROUST, 1987, p. 43, grifos meus) ${ }^{17}$

Saindo das trevas, de um tempo perdido, Combray é projetada em fragmentos, mas o considerável de seu todo permanece escondido na noite. Tais fragmentos são vistos apenas como um pano luminoso, um pano como aquele da Vista de Delft, de Johannes Vermeer. Novamente a pintura holandesa é evocada como uma via metafórica e metonímica para que o narrador pinte seus espaços, para que ele consiga escrevê-los detalhadamente. Esse mesmo significante pano luminoso é evocado como o espaço privilegiado da escritura, pois é ele que o personagem Bergotte, escritor em À la recherche, veria como modelo de perfeição e acabamento estéticos, ou seja, uma forma ideal de representação da arte, inclusive da escritura: "C'est ainsi que j'aurais dû écrire, se disait-il. Mes derniers livres sont trop secs, il aurait fallu passer plusieurs couches de couleur, rendre ma phrase en elle-même précieuse, comme ce petit pan de mur jaune" (PROUST, 1988,

\footnotetext{
17 "Assim, por muito tempo, quando despertava a noite e vinha a recordação de Combray, nunca pude ver mais que aquela espécie de lanço luminoso, recortado no meio de trevas indistintas, semelhante aos que acender um fogo de artifício ou alguma projeção elétrica alumiam e secionam em um edifício cujas partes restantes permanecem mergulhadas dentro da noite." (PROUST, 1982, p. 30, tradução de Mário Quintana, grifos meus). O termo lanço corresponde a "porção ou extensão de muro, parede etc. ger. entre dois elementos como pilastras e patamares; lenço, pano" (Dicionário eletrônico Houaiss da língua portuguesa 3.0).
} 
p. 692, grifos meus). ${ }^{18}$ As palavras de Bergotte parecem-nos dizer "eu deveria ter transmitido melhor, ter elaborado melhor, ter sido como Vermeer, ou seja, ter descrito melhor", uma vez que é a descrição que opera o texto em sua estrutura superficial e profunda, trazendo emoções, trazendo o objeto para fora da noite escura do tempo perdido e projetando-o como um fogo de artifício em um pequeno pano luminoso ou em uma parede como no episódio da lanterna mágica, enquadrando-o, dando-lhe contorno, enfim, fazendo-o simbolizado no espaço.

O espaço faz-se, no universo do narrador proustiano, uma tela sobre a qual ele pode

imaginer différentes plaques de verre peint, non dans le mouvement qui les projette les une après les autres sur une surface, mais arrangées les une à côté des autres, dans une ordre simultané. Somme toute, les verres de la lanterne offrent une collection de vitraux, comme l'église de Combray. (POULET, 1982, p. 115-6) ${ }^{19}$

Ao escolher espaços em branco para projetar o tempo, o narrador consegue se organizar face à fruição temporal. Tal organização se dá na medida em que o narrador, por uma justaposição de imagens, de espaços, de personagens, consegue transitar pelos estilhaços do tempo perdido e não mais ser apenas transitado por ele. Por essa via, o narrador é capaz de narrar Combray, suas lembranças dali, re-contar (sua) história, de colocar na ordem sistemática da linguagem a não sistematicidade do

18 "Assim é que eu deveria ter escrito, dizia consigo. Meus últimos livros são demasiado secos, teria sido preciso passar várias camadas de tinta, tornar minha frase preciosa em si mesma, como este panozinho de muro." (PROUST, 2002, p. 173, tradução de Manuel Bandeira e Lourdes Sousa de Alencar, grifos meus) 19 "Imaginar diferentes placas de vidro pintado, não no movimento que as projeta uma após a outra sobre uma superfície, mas dispostas uma ao lado da outra, em uma ordem simultânea. Em suma, os vidros da lanterna oferecem uma coleção de vitrais, como a igreja de Combray." (Tradução livre) 
tempo, pois "l'hystorisation se fait par les temps d'ouverture de l'inconscient dans lesquels la vérité se déplie dans la structure de langage; le thème est connu et fait déplorer les temps de fermeture" (SOLER, 2004, p. 42). ${ }^{20}$ Nesse sentido, "quand je vous parle de l'inconscient comme de ce qui apparaît dans la pulsation temporelle, l'image peut vous venir de la nasse qui s'entrouve, au fond de quoi va se réaliser la pêche du poisson (LACAN, 1973, p. 161). ${ }^{21}$ Nassa, o espaço; o peixe, o lampejo do tempo perdido. Vê-se que o inconsciente demanda uma topologia para se realizar, para que, enfim, sua fruição de tempo puro e real sofra um corte. Somente assim, o narrador poderia transitar pela catedral do tempo que o circunda; catedral

occupant, si l'on peut dire, un espace à quatre dimensions - la quatrième étant celle du Temps - déployant à travers les siècles son vaisseau qui, de travée en travée, de chapelle en chapelle, semblait vaincre et franchir, non pas seulement quelques mètres, mais des époques successives d'où il sortait victorieux. (PROUST, 1987, p. 60) ${ }^{22}$

20 “A 'historização' faz-se pelos tempos de abertura do inconsciente nos quais a verdade se desdobra na estrutura da linguagem, o tema é conhecido e lamenta os tempos de fechamento." (Tradução livre). O termo bystorisation, presente no ensino de Lacan e no texto de Soler, é uma própria poética da letra se movendo entre as palavras hystérie e historisation. Pode-se ainda observar que bystorisation envelopa o radical byst-formador do termo bisterização - em francês bysterization - que creio circular naquele significante. A bisterização pode ser vista como o ato de se colocar o discurso inconsciente em movimento na estrutura da linguagem e da língua a fim de se obter um saber outrora não sabido. 21 "Quando lhes falo do inconsciente como daquilo que aparece na pulsação temporal, pode nos vir a imagem da nassa que se entreabre, no fundo da qual vai se realizar a pesca do peixe." (LACAN, 1998, p. 137, tradução de M. D. Magno)

22 "Ocupava, por assim dizer, um espaço de quatro dimensões - a quarta era 0 tempo - e impelia através dos séculos a sua nave que, de abóboda em abóboda, de capela em capela, parecia vencer e transpor não simplesmente alguns metros, mas épocas sucessivas de onde saía triunfante." (PROUST, 1982, p. 41, tradução de Mário Quintana) 
Uma quarta dimensão instransponível, o Tempo, com maiúscula, sendo, assim, possível transitar apenas por três outras dimensões que são espaciais. Diante desse real impossível do tempo, da magnitude dessa catedral de quatro dimensões, agora não mais em Combray, mas na biblioteca da princesa de Guermantes, o narrador busca novamente um espaço em branco para projetar estilhaços do tempo a fim de fazer sua obra: "épinglant ici un feuillet supplémentaire, je bâtirais mon livre, je n'ose pas dire ambitieusement comme une cathédrale, mais tout simplement comme une robe" (PROUST, 1989, p. 610, grifos meus). ${ }^{23}$

Sempre acossado pelo tempo, buscando nomeá-lo em espaços, o narrador proustiano tem sua odisseia temporal. Outrora em uma parede, outrora em um pequeno pano luminoso e aqui em uma folba, enfim, uma narração articula-se no espaço para contornar o impossível do tempo. O "era uma vez" fundamental ao ato de narrar, de fabular, nunca se realiza fora de lugares imaginários. Pela edificação do espaço poético, o narrador busca o tempo perdido. Pela edificação do espaço poético, o narrador circunda fragmentos do tempo perdido; nassa e peixe se encontram. O espaço, então, torna-se a topologia proustiana para que seu narrador possa, sob essa égide, construir seu desejo de escritura frente à intransponível e real rocha do tempo.

\section{Referências}

\section{Marcel Proust}

PROUST, Marcel. Swann expliqué par Proust. In: PROUST, Marcel. Contre Sainte-Beuve. Paris: Gallimard, 1971.

PROUST, Marcel. Du côté de chez Swann I, pt. I. Paris: Gallimard, 1987. (À la recherche du temps perdu, v. 1).

23 "Pregando aqui e ali uma folba suplementar, eu construiria meu livro, não ouso dizer ambiciosamente como uma catedral, mas modestamente como um vestido." (PROUST, 2004, p. 280, tradução de Lúcia Miguel Pereira, grifos meus) 
PROUST, Marcel. Du côté de chez Swann I, pt. II. Paris: Gallimard, 1987. (À la recherche du temps perdu, v. 1).

PROUST, Marcel. La prisonnière. Paris: Gallimard, 1988. (À la recherche du temps perdu, v. 3).

PROUST, Marcel. Le temps retrouvé. Paris: Gallimard, 1989. (À la recherche du temps perdu, v. 4).

PROUST, Marcel. Correspondance de Marcel Proust - 1919. Texto estabelecido, apresentado e anotado por Philip Kolb. Paris: Librairie Plon, 1990. Vol. XVIII.

PROUST, Marcel. Correspondance de Marcel Proust - 1920. Texto estabelecido, apresentado e anotado por Philip Kolb. Paris: Librarie Plon, 1991. Vol. XIX.

PROUST, Marcel. La confission d'une jeune fille. In: PROUST, Marcel. Les plaisirs et les jours. Paris: Gallimard, 1993.

\section{Traduções de obras que foram utilizadas no original}

LACAN, Jacques. O seminário: livro 11 - Os quatro conceitos fundamentais da psicanálise. Texto estabelecido por Jacques-Alain Miller e tradução de M. D. Magno. Rio de Janeiro: Jorge Zahar, 1998.

PROUST, Marcel. No caminbo de Swann. Trad. Mário Quintana. São Paulo: Abril Cultural, 1982.

PROUST, Marcel. A prisioneira. Trad. Manuel Bandeira e Lourdes Sousa de Alencar. São Paulo: Globo, 2002.

PROUST, Marcel. O tempo redescoberto. Trad. Lúcia Miguel Pereira. São Paulo: Globo, 2004.

\section{Outros}

AGOSTINHO, Santo. Confissões. Rio de Janeiro: Vozes, 2000.

BARTHES, Roland. O grau zero da escrita. Trad. Mário Laranjeira. São Paulo: Martins Fontes, 2000.

BIZUB, Edward. Proust et le moi divisé: la "Recherche": creuset de la psychologie expérimentale (1874-1914). Genève: Droz, 2006. 
FRANK, Joseph. Spatial form in Modern Literature. The Sewanee Review, Baltimore, v. 53, n. 2, p. 221-240, 1945; v. 53, n. 4, p. 643-653, 1945.

FREUD, Sigmund. Sobre a transitoriedade. In: FREUD, Sigmund. Obras completas. Rio de Janeiro: Imago, 1976. Vol. XIV.

HAMON, Philippe. Du descriptif. Paris: Hachette, 1993.

LACAN, Jacques. Le séminaire: livre XI - Les quatre concepts fondamentaux de la psychanalyse. Paris: Seuil, 1973.

LESSING. G. E. Laocoonte - ou sobre as fronteiras da pintura e da poesia. Introdução, tradução e notas de Márcio Seligmann-Silva. São Paulo: Iluminuras, 2011.

MEYERHOFF, Hans. O tempo na literatura. Trad. Myriam Campello. São Paulo: McGraw-Hill do Brasil, 1976.

POULET, George. L'espace proustien. Paris: Gallimard, 1982.

SOLER, Colette. Temps, pas logique. Hétérité: Revue de Psychanalyse, Paris, n. 7, p. 38-43, 2004. Disponível em: < http://www.champlacanien.net/ public/docu/1/ heterite7.pdf $>$. Acesso em: 20 jan. 1012.

WILLEMART, Philippe. Proust, poeta e psicanalista. São Paulo: Ateliê, 2000.

Recebido para publicação em 28 de fevereiro de 2012 Aprovado em 24 de maio de 2012 